\title{
HISTÓRIAS VIVIDAS E MEMÓRIAS
}

\author{
Graciette Lamas Esposito ${ }^{1}$ \\ Andréa Kruger Gonçalves²
}

resumo

Este estudo objetiva estabelecer relações entre as memórias evocadas e as histórias de vida de idosos institucionalizados. Apresenta uma abordagem qualitativa de base fenomenológica, relacionando seis moradores de uma Instituição de Longa Permanência para Idosos (ILPI), todos com capacidade cognitiva preservada. A técnica aplicada na pesquisa é de entrevistas narrativas, utilizando como fonte de dados a narrativa biográfica abrangente. São analisadas categorias a priori, como institucionalização, relações familiares e memória do trabalho, e a posteriori, como tempo, saúde, memória histórica e solidão. Na análise dos resultados obtidos, é demonstrada estreita relação entre as histórias e as reminiscências relatadas. As narrativas trazem à luz o percorrido até a institucionalização.

1 Graduada em Pedagogia. Especialista em Envelhecimento e Qualidade de Vida pela Escola de Educação Física da Universidade Federal do Rio Grande do Sul (UFRGS). E-mail: graciesposito@ gmail.com

2 Graduada em Educação Física. Doutora em Psicologia. Docente do Mestrado em Saúde Coletiva da Universidade Federal do Rio Grande do Sul (UFRGS), com vínculo ao Departamento de Educação Física da UFRGS. E-mail: andreakg@ufrgs.br 
O mundo dos velhos, de todos os velhos é, de modo mais ou menos intenso, o mundo da memória. (BOBBIO, 1997, p. 30).

\section{Introdução}

O crescimento expressivo da população idosa nas últimas décadas propicia reflexão sobre a situação dos velhos em diferentes áreas e traz novos desafios, entre eles as questões sociais e de saúde para a melhora e permanência da qualidade de vida, pois é uma fase reconhecida por intensas mudanças físicas e psicológicas e fechamento do ciclo vital. O aumento da longevidade dos idosos, justificada pela redução da mortalidade e do número de nascimentos, fenômeno mundial e brasileiro amplamente divulgado, nos leva a compreender a importância do tema e de estudos realizados, e torna-se imperativa a busca de pesquisas, ideias e ações que valorizem esses idosos. A ciência avança a passos largos na questão preventiva de doenças físicas e emocionais desta faixa etária, e é de suma importância dar voz aos velhos e suas recordações, sem preconceitos, pois os conhecendo mais profundamente, traçamos estratégias para o melhor cuidado.

Este estudo versa sobre memórias e histórias de vida de um grupo de seis idosos moradores em uma instituição de longa permanência para idosos (ILPI), na cidade de Porto Alegre, Rio Grande do Sul. Utiliza-se o método de pesquisa qualitativa e técnica de entrevistas narrativas, gravadas e transcritas para análise, apontando-se categorias a priori e a posteriori.

Esta pesquisa parte do interesse das autoras em conhecer e aprofundar esta etapa de vida - a velhice - tanto por meio de leituras e reflexões como pela convivência com idosos. Tem por objetivo estabelecer relações entre as memórias evocadas e as histórias de vida. Visa, além disso, buscar significados ao longo do caminho percorrido com as marcas da experiência, resgatar lembranças, dar vazão às emoções e aos sentimentos, ressignificar as manifestações da memória e, ainda, contribuir com o acervo de memórias coletivas de fatos históricos vivenciados.

No panorama teórico estudado, foram utilizados os autores Ecléa Bosi, Norberto Bobbio, Ana Amélia Camarano, Maurice Halbwachs e outros interessados em estudos sobre histórias de vida, memórias, velhice e instituições de longa permanência para idosos. 
O Brasil, em 2025, terá a sexta população de idosos do mundo, cerca de 32 milhões de pessoas (FERREIRA et al., 2010). Esse envelhecimento se deve a modificações expressivas nas condições socioeconômicas e de saúde da população mundial, o que altera a estrutura demográfica, acarretando um crescimento significativo da população idosa. A expectativa de vida é mais alta, tanto pela queda da mortalidade, devido à melhoria dos avanços da medicina, ao acesso facilitado à saúde e à divulgação de tratamentos médicos pela mídia, como pela redução das taxas de natalidade.

Segundo Camarano e Kanso (2010), a velhice se caracteriza por perdas progressivas de funções e de papéis sociais, como cessação do trabalho, declínio do corpo, autonomia, lutos, constituindo-se em um processo único para cada indivíduo, pois depende de capacidades básicas adquiridas ou provenientes do meio ambiente.

A população idosa se torna assunto de discussão nas áreas de política da saúde e social, porém vista como um problema previdenciário e de saúde pública, como alertam Souza et al. (2002) ${ }^{3}$ apud Guerra e Caldas (2010). No mesmo artigo, Motta (2006, p. 2.932) ${ }^{4}$ apud Guerra e Caldas (2010) reforça que "a velhice é constantemente associada não somente a desgaste e decadência física, mas também à doença, dependência e fealdade". Há uma visão preconceituosa a respeito do envelhecimento, com informações insuficientes para a população em geral, gerando significados e imagens negativas, pouca penetração social e pouca visibilidade política e, como principal característica, o isolamento social.

Entretanto, notam-se, de modo simultâneo, movimentos contrários que lutam contra esse isolamento. Há necessidade de incluí-los em programas governamentais e particulares que proporcionem melhor qualidade de vida: social, saúde e educação, favorecendo um estilo de vida ativo e saudável. Políticas públicas apropriadas preservam os direitos da população idosa como o Estatuto do Idoso (BRASIL, 2003), que, segundo o Ministério da Saúde (BRASIL, 2010, p. 7), “...é uma referência para o movimento social na área, servindo como guia para que as políticas públicas sejam cada vez mais adequadas ao processo de ressignificação da velhice".

3 SOUZA; Edinilsa Ramos de; MINAYO, Maria Cecília de Souza; XIMENES, Liana Furtado; DESLANDES, Suely Ferreira. O idoso sob o olhar do outro. In: MINAYO, Maria Cecília de Souza; Coimbra Jr., Carlos E. A. (Org.). Antropologia, saúde e envelhecimento. Rio de Janeiro: Editora Fiocruz; 2002. p. 191-209. Apud GUERRA; CALDAS, 2010.

4 MOTTA, Alda Britto da. Visão antropológica do envelhecimento. In: FREITAS, Elizabete Viana de (Org.). Tratado de Geriatria e Gerontologia. 2. ed. Rio de Janeiro: Guanabara Koogan, 2006. p. 78-82. Apud GUERRA; CALDAS, 2010. 
O Estatuto do Idoso, em parágrafo único, art. 3, item $\mathrm{V}$, prioriza o atendimento do idoso pela família, em detrimento do atendimento asilar. Born e Boechat (2011) enfatizam que houve um declínio na capacidade da família para prestar o cuidado aos mais velhos e os núcleos familiares se alteraram de forma significativa, com novos valores sociais e mais individualismo. Muitas vezes, torna-se inviável a sustentação do apoio familiar que proporcione cuidados de saúde, convivência saudável e lazer, base financeira, portanto, uma boa qualidade de vida. No entanto, a mudança para uma ILPI pode ser traumatizante em razão da ruptura de laços, vínculos familiares - viuvez, saída dos filhos de casa - e amizades de toda uma vida.

Uma pesquisa nacional, de caráter censitário e descrita por Camarano e Kanso (2010), define o modelo atual de atendimento das ILPI brasileiras. A maioria das instituições é de natureza filantrópica, refletindo a origem ligada aos asilos, direcionados à população carente. Isso comprova que carência financeira e de moradia estão entre os motivos mais importantes para a busca por essas instituições. As autoras ressaltam também que, no Brasil, ainda não há um consenso sobre o que são as ILPI, pois seria necessário oferecer algo mais do que um abrigo, a rede de assistência social integrada à rede de assistência à saúde. Elucidam, ainda, o conceito de ILPI para a Agência Nacional de Vigilância Sanitária (ANVISA), que são "instituições governamentais ou não governamentais, de caráter residencial, domicílio coletivo de pessoas com idade igual ou superior a 60 anos, com ou sem suporte familiar, em condição de liberdade, dignidade e cidadania" (CAMARANO; KANSO, 2010, p. 190).

Goffman (2010, p. 11) usa o termo "instituição total", referindo-se às ILPI "[...] como um local de residência e trabalho onde um grande número de indivíduos com situação semelhante, separados da sociedade mais ampla por considerável período de tempo, leva uma vida fechada e formalmente administrada". A vida se desenvolve com um grande grupo de pessoas tratadas igualmente, obrigadas a fazer atividades em conjunto, em horários pré-definidos e com regras cumpridas sob vigilância. Reflete-se que, para indivíduos acostumados a gerir a própria vida, são alterações bem importantes no modo de viver.

Camarano et al. (2010, p. 189) questionam a visão de Goffman e consideram que as evidências não confirmam "o grau de totalidade" das instituições, pois esse fato dependeria do grau de dependência dos residentes: “Os que estão acamados têm sua vida administrada pela instituição, no entanto isto é decorrente da falta de autonomia e não necessariamente, por residirem em uma instituição."

Para idosos institucionalizados, o contato com o mundo externo é restrito, visitas de familiares são poucas ou nenhuma e a instituição se torna a família. 
A maioria convive apenas com os demais moradores e a equipe de funcionários, voluntários e estagiários. Entretanto, na instituição, há uma integração rica com bailes, festas temáticas, bingo e sessão de cinema, o grupo, assim, ganha vida e uma dinâmica própria, ou seja, um lugar para morar na velhice.

Bosi (1994, p. 83) reflete sobre a importância de responsabilidades, trabalho e interesses para os idosos, o que tornaria a sobrevivência mais digna, com estímulos. Elucida, ainda, que "[...] se o idoso perde o seu lugar social, e num momento que deveria ser ao contrário, há uma perda e um empobrecimento para todos". Ressalta que esse é o momento de ouvir as histórias, da infância contada e recriada, de fatos históricos vividos, e o tempo de lembrar e resgatar a riqueza e a diversidade de seu mundo social.

Sobre a memória, Bosi (1994) cita Halbwachs ${ }^{5}$, importante teórico psicossocial que descreveu e avaliou a memória como espontânea, de caráter livre e excepcional. Este vincula a memória da pessoa à memória do grupo, e esta última à memória coletiva de cada sociedade. A memória de cada um dependerá dos relacionamentos familiares e dos grupos de relações sociais como igreja, escola e grupos de referência individuais. Bosi (1994) ainda nos esclarece que o maior número de lembranças que evocamos é provocado pela situação presente, relacionados a pessoas conhecidas, pais e amigos e realça que, ao desencadear o curso da memória, a iniciativa da vida atual se altera. Compara, também, a reconstrução do passado a uma releitura, ou seja, em que parece que estamos lendo um livro novo ou até remanejado. Ressalta que o conjunto de nossas ideias atuais impediria de recuperar exatamente as impressões e os sentimentos experimentados a primeira vez, havendo uma impossibilidade de reviver o passado tal e qual.

A memória dos idosos é um legado que deve ser sempre valorizado, pois através de evocações e narrativas do passado teremos acesso ao conhecimento e a experiências significativas, desvendando os antepassados, as comunidades e acontecimentos da história vivenciados por eles. Essa é a memória que socializa o idoso, que traz para os descendentes a maneira de pensar e agir de outra época, uma época que ficou lá atrás e que vai reacender nas pequenas ações do dia a dia e também em comemorações das comunidades, os rituais quase esquecidos. Essa memória, que socializa, também integra as gerações.

5 HALBWACHS, Maurice. La mémoire collective. Paris: PUF, 1964. Apud BOSI, 1994. 
Este estudo tem uma abordagem qualitativa, com uma concepção fenomenológica, buscando a essência do fenômeno, neste caso, a história e construções de vida de idosos institucionalizados. Gil (2011, p. 15) nos esclarece que "[...] a pesquisa fenomenológica parte do cotidiano, da compreensão do modo de viver das pessoas".

A técnica aplicada para a pesquisa foi de entrevistas narrativas, utilizando como fonte de dados a narrativa biográfica abrangente (FLIK, 2009). Estabeleceu-se uma amostragem por conveniência, sendo entrevistados Ada, Clea, Irma, Lia, Décio e Ivan ${ }^{6}$. Iniciou-se a entrevista com a questão gerativa: "Quero que você me conte a história de sua vida; a melhor maneira de fazer isso é começar com dados de seu nascimento, fatos da infância, passando por todas as coisas que aconteceram, até os dias atuais, podendo levar o tempo que for preciso."

Utilizou-se a classificação por categorias, distinguindo-as a priori, como institucionalização, relações familiares e memória do trabalho, e a posteriori, como tempo, saúde, memória histórica e solidão. Foram relacionadas entre si, analisando se houve interferência e alguma coisa em comum (se uma poderia ser causa/efeito da outra).

\section{Reminiscências e retratos das histórias ser idoso institucionalizado}

Nas estradas desta vida/ Só espinhos eu encontrei/ Mas deles já faço flores/ Só assim eu viverei/ Os amores que eu tive/ Como uma fonte secou/ Que as águas se foram embora/ e só a saudade ficou...

Considerando-se que as histórias e construções de vida em entrevistas narrativas compreendem construções subjetivas e sociais, os objetivos da análise dos dados narrativos são revelar processos construtivos, e não factuais.

A análise desta pesquisa teve a seguinte sequência: análise de dados biográficos, que são os dados dos eventos significativos citados pelo entrevistado, como uma exposição cronológica; análise do texto e do campo temático, incluindo a autoapresentação e reconstrução da história de vida como foi vivida; e, ainda, análise detalhada de situações individuais textuais.

6 Os nomes são fictícios. 


\section{4,1,1 Institucionalização e relações familiares}

Analisadas em conjunto por haver uma ligação muito intensa entre as duas, uma análise das relações familiares antes e depois da institucionalização. Quanto ao tempo de moradia, quatro deles moram entre seis meses e um ano, e duas mulheres encontram-se há quatro e oito anos e meio, respectivamente.

Décio (74 anos) é um homem de aparência saudável, queixoso, se locomove pela instituição com desenvoltura, tem permissão para sair e frequenta a Igreja Evangélica. Relata problemas anteriores de agressividade com a segunda esposa e vizinhos. Teve três filhos, porém não refere convivência com estes. A situação socioeconômica determinou a necessidade e o motivo de mudar-se para a ILPI, sendo encaminhado pelo serviço social da corporação militar à qual é vinculado pela aposentadoria. Narra: "Comecei a tirar empréstimo, e se transformou numa bola de neve, fiquei sem dinheiro para o aluguel e as refeições." O crédito, para Décio, apesar das necessidades atendidas na época, comprometeu seriamente a renda mensal e, sem ajuda de familiares, não teve escolha a não ser ir morar na instituição.

Buaes (2011) pesquisou sobre educação financeira de idosas e, em sua tese, apresenta alguns dados sobre o endividamento de aposentados e pensionistas a partir da facilidade do crédito consignado. Os empréstimos são tomados pelos segurados com faixa etária entre 60 e 79 anos e parcelados de 49 a 60 meses, o que acarreta uma redução importante na renda. As instituições financeiras utilizam estratégias de marketing questionáveis para oferecerem empréstimos sem que os idosos tenham uma noção clara do que significa o impacto do crédito para suas aposentadorias nos próximos anos, como aconteceu com Décio.

Romero et al. (2010, p. 267) divulgam que "histórias de vida familiares conflituosas, especialmente de idosos do sexo masculino, antecedentes de violência contra a mulher e/ou filhos e abandono da família em etapas anteriores da vida são motivos frequentes do abandono do idoso", o que também explica a institucionalização de Décio.

Cléa (78 anos) foi institucionalizada meses depois da viuvez, há quatro anos. Convive com o neto, a filha única e o genro em muitos finais de semana, na casa deles. Descreve carinho entre todos: "Ela telefona todos os dias para mim." Relata que foi dela a iniciativa de se institucionalizar, o que fica claro em sua fala: "Em primeiro lugar, eu não tinha horário para nada, nem para levantar, comer, minha filha trabalha. Entrei em depressão, aí eu vim para cá." 
A entrevistada Irma (83 anos) mantém contato telefônico com o filho que mora em São Paulo e, sobre a filha, conta que havia conflitos na relação. Apesar disso, o suporte em relação aos remédios e outros cuidados partem da filha. Relembra os fatos que a levaram à institucionalização: "Eu gostava de estar perto dos filhos. Para não incomodar eu não quis morar com o filho em São Paulo. Eu me arrependo muito, o único filho homem, mas estou me dando bem aqui, gostei." Embora Cléa e Irma tenham escolhido o lugar para morar na velhice, fica claro que se existisse outra solução, teriam ficado perto dos familiares.

Ada (93 anos) é divorciada e teve outros irmãos, mas hoje somente a irmã caçula vive. Relaciona-se através de contatos semanais com o filho e um sobrinho. Evita falar na filha, pois conta que partiu desta a ideia da internação. Como as idosas anteriores, narra que a institucionalização aconteceu porque não tinha quem a cuidasse e com os filhos não deu certo. Parece conformar-se: "Ninguém gosta de cuidar de velho (risos). Aqui 'tá bom, cuidam bem, almoço e café bons, tem essas amigas, né, jogo bingo, pior do que estar sozinha..."

Camarano e Scharfstein (2010) explicam que a residência em uma instituição nem sempre exclui o idoso do contexto social ou é uma ruptura de laços com familiares e amigos. Os vínculos familiares podem ser mantidos e novos laços podem ser criados, como é o caso de Ada, quando diz que tem as amigas e o bingo, corroborando com o que as autoras se depararam na pesquisa realizada em diversas ILPI. Outro dado importante que aparece na pesquisa das autoras, um dos motivos da institucionalização e que também se constata nas narrativas, é a dificuldade do cuidado ser realizado pelos familiares e a preocupação de causar incômodo para eles, como fica claro na fala de Irma - "para não incomodar".

Ivan (64 anos) relata que perdeu a mulher e os irmãos: "Morreu tudo, só fiquei eu [...] casaram, viveram, eu tenho sobrinhos." Conta que uma sobrinha o convida para ir até sua casa, porém ele não aceita, prefere ficar sempre na instituição e enfatiza que não quer mais sair dali, e seu relacionamento é com os amigos que fez ali. Viúvo e sozinho, sem cuidados, conta que começou a beber e, aborrecido, saía para a rua, não lembrando onde estava: "Fui perdendo o tino da cabeça, não sabia mais o que "tava fazendo e acabei aqui."

Ao analisarem homens residentes em abrigos e instituições, Camarano e Scharfstein (2010, p. 168) observaram que quatro entre cinco entrevistados “[...] tiveram ao longo de suas vidas uma situação socioeconômica razoável, constituíram família, mas se tornaram alcoólatras e perderam tudo, inclusive laços familiares". Relatam que o alcoolismo foi consequência de uma importante perda amorosa, o que se percebe no caso do Ivan, que, após a viuvez, perdeu o controle da própria vida. 
Lia (86 anos) ainda tem uma irmã que a visita, enquanto outras moram longe. Fala da neta, sente falta das bisnetas, e comenta sobre isso em versos: "Saudade é palavra doce / Mas ela é amarga também / Ela é doce pra quem ama". No entanto, entende a neta, pois esta "não pode vir me ver, ela trabalha, eu perdoo, é uma vida muito corrida", conforma-se. Foi levada para a instituição pela filha que estava com câncer e que não tinha mais condições de cuidá-la, pois, na época, se recuperava de uma queda. Meses depois, a filha faleceu.

Isso é muito comum de acontecer, ou seja, o idoso com perdas na autonomia e falta de familiares que se dediquem a ele e possam ajudá-lo. Os casos de Ivan, Lia e Ada são reforçados pelo que aparece nas pesquisas de Camarano e Scharfstein (2010): a dificuldade de a família cuidar é um dos motivos alegados para a aceitação da moradia em uma instituição. Pelas narrativas sobre os motivos da institucionalização e também das relações familiares, intuem-se alguns relacionamentos tumultuados e estremecidos entre pais, filhos ou outros parentes, embora alguns entrevistados recebam atenção familiar. Através de suas evocações e falas, nota-se que muitos têm saudade da convivência com os parentes.

\subsubsection{Memória do trabalho}

“O trabalho configura-se como ação humana de domínio e transformação da natureza, para satisfazer necessidades", conforme Lamas (1997, p. 43). Através do trabalho, são construídos objetos de cultura, além de nossa própria identidade. É a base da sobrevivência e do ganho pecuniário. Todos os entrevistados narram um trabalho, manual ou mecânico, ou uma carreira realizada ao longo da vida como forma de prover a subsistência.

Décio começa a trabalhar bem jovem no interior do Estado, em olarias, fábrica de bebidas e, aos dezoito anos, serve ao Exército. Segue um tempo na carreira militar, depois ingressa na Brigada Militar em Porto Alegre e fica até se aposentar. É interessante salientar que toda narrativa foi permeada por falas de que sempre se sentia explorado, sendo que o idoso relata divergências no trabalho e que foi muito prejudicado por atitudes de não sujeição aos superiores.

Ada trabalhou no comércio de Porto Alegre como arquivista e telefonista, e também em uma companhia de seguros. Cléa foi empregada doméstica, cozinheira e babá, uma pessoa servil por toda uma vida, diferentemente de Décio. Cléa conta que sempre foi reconhecida pelas patroas, que a ampararam nos momentos em que precisava. Irma (83 anos) narra seus fazeres, ainda muito intensos em sua memória: "Fui costureira desde os quinze anos, acho bonito arrumar a mulher bem elegante, até vestido de noiva fiz, coisa mais linda, e 
as fotos, então, nem parecia eu que tinha feito, parecia um sonho, diziam que eu tinha mãos de fada, caprichosa."

Bosi (1994, p. 474) comenta a respeito das recordações de seus entrevistados sobre situações de trabalho: "A recordação é tão viva, tão presente, que se transforma no desejo de repetir o gesto e ensinar a arte a quem o escuta." Irma fala de seus dons de costureira com brilho no olhar, com saudade do tempo em que vestia as mulheres com tecidos e bordados confeccionados com esmero, mostrando que as lembranças ainda estão muito vivas. Ela recebe aposentadoria pela Previdência Social.

Ivan também começa a trabalhar muito cedo, como todos os entrevistados, e desde os quinze anos atuava como operador de máquina de cinema em Porto Alegre. Como não é alfabetizado, teve dificuldades em conseguir empregos, porém estabilizou-se em oficina mecânica até se aposentar. Também possui proventos de aposentadoria.

Lia trabalhava na lavoura com o pai desde os oito anos de idade e, na fase adulta, já casada, trabalhava para o marido, conforme relata: "Fazia sabão, trabalhava na roça, no engenho, dava sal pro gado, fazia doce, trabalhava como empregada, era o pião dele. Fiquei 12 anos com ele." Trabalhou também na sua cidade, no interior do estado, onde cuidava de crianças em casa de família. Depois, foi para Porto Alegre à procura dos direitos trabalhistas, da carteira assinada. Conta: “Eu não tenho queixa daqui, encontrei só gente boa, cuidei os filhos dos outros, trabalhei no Gigantinho, em restaurante, e me aposentei em firma de limpeza." Além do salário da aposentadoria, recebe um pecúlio mensal por causa de um acidente de trabalho.

\subsection{Categorias a posteriori}

\subsubsection{Tempo}

Conforme os entrevistados iam contando suas histórias de vida, percebe-se a dinâmica do tempo nas narrativas: ele se torna fluído, com margens cronológicas borradas. Há etapas das vivências e fatos evocados organizando e sistematizando a vida. A memória dos acontecimentos demarca a história de vida, como relembra Bosi (1994) ao comentar sobre o tempo social, que absorve o tempo individual que se aproxima dele. O tempo é vivido por cada grupo de maneira diferente: o tempo da família, da escola ou do trabalho não é percebido exatamente igual em meios e lugares diferentes.

No estudo sobre memórias de velhos, a autora menciona esta impressão da divisão do tempo que as lembranças deixaram. A pesquisadora ilustra que 
a infância tornou-se "larga, quase sem margens, e é difícil transpor a infância e chegar à juventude" (BOSI, 1994, p. 415), todavia cita que a juventude e a idade madura já são transpostas com mais rapidez e, quando chega o momento de contar sobre a velhice, os acontecimentos ficam menos interessantes, com narrativas sempre iguais, "fazendo-nos pensar num remanso da correnteza". Logo depois, afirma que não é como pensamos, "é o tempo que se precipita, que gira sobre si mesmo em círculos iguais e cada vez mais rápidos sobre o sorvedouro". A metáfora aponta para o que aconteceu na escuta e transcrição das entrevistas narrativas realizadas na instituição, pois as lembranças realmente iam e vinham no tempo, rápidas, como em círculos, às vezes emocionados, ou entre risos, orgulhosos ou, ainda, ressentidos com suas histórias de vida.

A evocação das lembranças, na maioria das vezes, sucede-se por etapas e, como assinala a autora citada, possui igual força como a divisão do tempo: a memória vai-se dividindo em pontos, signos mnemônicos e marcações nas quais as vivências têm maior significado, como mudanças de casa ou lugar, morte familiar, casamentos, empregos e festas.

Das seis entrevistas realizadas nesta pesquisa, quatro evocam a morte de um parente já na autoapresentação, evidenciando-se o valor das perdas como um marco na vida de cada um.

Na narrativa de Ada sobre uma festa popular, percebe-se a sucessão do tempo e as etapas vividas e, através de sua fala, compreende-se que a idosa evoca o fim da infância ao contar que tudo terminou, aproximadamente aos onze ou doze anos, marcando bem a divisão do tempo: "Na Redenção, teve uma festa em 1930, fizeram tantos stands, a coisa mais linda, sabe, eu me lembro, a entrada era 5 cruzeiros, a gente era aluna, davam presentes, amêndoa, castanha, coisa boa, terminou tudo... morrem as pessoas, os mais novos não se interessam." A evocação de Ada das festas coletivas e populares, que na época eram realizadas na rua, é muito interessante, pois são marcas daquele tempo.

Cléa, quando se reporta à morte da mãe e do avô de febre do tifo, que contaminou muita gente na época, entende que não é uma lembrança própria pela pouca idade que tinha. A senhora de agora evoca esse acontecimento tão marcante porque se remete inteiramente à memória dos outros, pois ao explicar "dizem que eu tinha dois anos quando eles morreram", esclarece que alguém, não especificado por ela na entrevista, contou o episódio. Neste caso, o narrador, a avó ou outro familiar, transmitiu uma informação de real importância para a construção da história de vida. Halbwachs (2011) analisa a transmissão da tradição e, segundo ele, a ligação transgeracional é uma forma de transmitir a história e a memória familiar, e isto bem ilustra as evocações de Cléa em relação aos fatos passados de sua tenra infância. 
Os seis idosos entrevistados, com uma exceção, relatam dores em geral, as quais acompanham doenças crônicas degenerativas, típicas da velhice. Duarte et al. (2010, p. 123) comentam que "[...] o envelhecimento pode aumentar a prevalência de doenças e agravos crônicos não transmissíveis, muitos deles culminando com sequelas limitantes de um bom desempenho funcional [...]", podendo gerar situações de dependência e necessitando de cuidados.

Ada é a única participante que não relata problemas de saúde. Décio diz ter diabetes e consequentemente problemas de visão. Menciona pressão alta, problemas no joelho e dores nas pernas: “Tem dia que tem que 'tá orando. Sinto dor aqui, acolá, sei lá o quê."

Na autoapresentação, Cléa conta que teve a febre do tifo na mesma época em que perdeu sua mãe e seu avô com essa febre, conforme relatado anteriormente. Também teve tuberculose no início da fase adulta e, já casada, teve um infarto. Quebrou a perna e não pôde operar por causa da osteoporose, anda com auxílio de uma bengala e tem sequelas do acidente.

Irma menciona gripes, problemas pulmonares e pressão alta. Percebe sua saúde como frágil e conta que quando está doente, a levam para a ala dos acamados, onde é muito bem cuidada: "Aí cuidam da gente, da alimentação, horários dos remédios, aí vale a pena, aqui é muito bom, eu gostei." Percebe-se no relato que se sente muito bem cuidada na instituição quando está doente, como se em outros momentos não fosse tão bom.

Ivan queixa-se de artrite no joelho, que lhe causa imobilidade, às vezes fica na cama por três dias pela dor e, então, é medicado. Conta que sofreu um acidente quando era bem jovem que lhe deixou sequelas: "Eu finquei um pau aqui atrás, encolheu os nervos, eu nunca fui ao médico. Meu pai não ligava muito pra essas coisas..." A deambulação é claudicante, no entanto, se locomove rapidamente e não gosta de demonstrar a dificuldade.

Lia quebrou o fêmur há onze anos ao ser atropelada e, um tempo depois, caiu e fraturou a coluna. Hoje em dia, caminha com dificuldade e apoia-se em muleta. Já operou os olhos por problemas de glaucoma e catarata, com a retina sendo o problema atual e sem cura: "A doutora veio, trouxe medicação pra não perder a vista, mas com tudo eu enxergo meio apagado." Uma médica oftalmologista voluntária acompanha o seu caso e doa a medicação.

Os idosos entrevistados apontam em suas narrativas que se sentem bem na instituição quanto aos cuidados com a saúde, pois têm atendimento médico, fisioterapia e remédios quando necessário, enfermagem 24 horas, odontologia três vezes por semana, massoterapia, cuidados com a beleza e lazer, além de grupos de dança e apresentações artísticas. 
Em relatório social de 2011, a instituição se apresenta e descreve seu objetivo, que é acolher o maior número de idosos, proporcionando-lhes abrigo, proteção e qualidade de vida. Tem como missão prestar auxílio, serviço e assistência a idosos em situação de vulnerabilidade social, sem distinção de raça, cor ou religião. Pelos dados colhidos durante as entrevistas narrativas, percebe-se que os objetivos e valores institucionais são cumpridos.

\subsubsection{Memória histórica}

A única entrevistada que evocou lembranças de acontecimentos históricos da época da infância, juventude e fase adulta foi Ada. Desde menina, em suas recordações, já participava de festas de rua e quermesses da Igreja São Pedro, com os pais e irmãos. Evoca alguns fatos que aconteceram em Porto Alegre, como em 1930, aos 12 anos: "Aí eu subi numa ameixeira, era alta, e lá no morro, tinha o quartel do Exército na Aparício Borges, aí eu vi a revolução, eles começaram a dar tiro, a cavalo e a pé, morreu muito brigadiano." Relata a enchente de 1941, também em Porto Alegre, aos 22 anos: "Barbaridade, veio até ali no Edifício Guaspari, como tinha água, e passavam os bichos que morreram, das fazendas, muita gente perdeu gado, bah, coisa triste. Eu vi coisa que muita gente não viu."

Ada foi espectadora de acontecimentos em épocas diferentes e, provavelmente, não tinha consciência da importância desses como fatos históricos, como a imagem de uma cena isolada da Revolução de 1930. Halbwachs (2011, p. 82) esclarece que a criança, mais tarde, "[...] quando escutar a descrição dos fatos se dará conta que apareciam como o início de um período político muito agitado e de uma importância decisiva". Reforça que é da própria lembrança que verá despontar o significado histórico. As crianças, ao perceberem as atitudes dos adultos diante dos fatos dos quais foram espectadores, percebem que eles mereciam ser retidos, prossegue o autor, e, mais tarde, compreenderão melhor por quê.

Ao evocar a enchente de 1941, Ada conta que viu muitos acontecimentos que a impressionaram. É possível que não tenha presenciado a todos, pois muitas vezes, quando evocamos fatos históricos, nos remetemos à memória coletiva compartilhada com os outros, "[...] tomamos emprestado de nosso ambiente, trazemos uma bagagem de lembranças históricas que podemos aumentar por meio de conversas ou de leituras" (HALBWACHS, 2011, p. 73).

A entrevistada evoca muitos acontecimentos do passado já citados neste trabalho, que não fizeram parte de sua história pessoal de vida, e sim de uma memória social e histórica. O mesmo autor nomeia a memória pessoal como autobiográfica e ainda reforça que esta última recebe ajuda da memória histórica - mais extensa - "[...] já que, afinal de contas, a história de nossa vida faz parte da história em geral" (HALBWACHS, 2011, p. 73). 
Sentimento que não se pode deixar de mencionar, pois fica muito nítido nos relatos. Décio explica: "Então eu larguei a minha família de mão. Minha família é os asilados aqui, é os irmãos da igreja." Lia faz poemas que evidenciam a solidão, arte que a ocupa e alegra muito: "Fiquei sozinha no mundo como uma ave sem ninho, sem ter a felicidade, nem amor e nem carinho." Irma explica que ficou só e não tem mais com quem morar: "Eu sempre gostava de estar perto dos parentes, aí...", prossegue comentando a perda das irmãs, companheiras que a acolheram por um tempo; são perdas significativas, pois, a partir delas, a vida se altera radicalmente com a mudança para a instituição. Ivan comenta: "Só fiquei eu. Quero morrer aqui", ao relatar a perda de todos os irmãos, já no início da entrevista.

Bosi (1994, p. 432) também refere que "os coetâneos vão morrendo, o afastamento de parentes e amigos é visível na etapa final das lembranças". As entrevistas narrativas deste estudo foram permeadas por recordações perceptíveis como estar sozinho, desamparado e abandonado na instituição.

\section{Considerações finais: memórias que desenham vidas}

Retorna-se à epígrafe de Bobbio - a quem se entrega a tarefa de introduzir este artigo - , a qual nos diz que, ao envelhecer, se tem o mundo da memória nas mãos. Lia nos ensina, ao brindar-nos com a criação de seus versos - epígrafe do capítulo quatro - que sempre é tempo de produzir e que a memória e cognição preservadas auxiliam a ultrapassar os muros da instituição para o contato com o mundo externo, já que os olhos já não podem vê-lo com tanta nitidez.

Os relatos das histórias de vida ajudam a entender o motivo da institucionalização. As histórias diferem entre si, apenas unidas pelo local de moradia, agora comum a todos. As condições de vida atuais são parecidas e todos demonstram resignação, apesar de estarem ali por situações diferenciadas. Foram ressaltados motivos que os encaminham à atual moradia como a própria escolha, por estar com a saúde frágil, ter assistência vinte e quatro horas e não querer ser um problema para a família; os que perderam os vínculos familiares e não têm onde residir, pela situação socioeconômica; e, ainda, a falta de condições das famílias para o cuidado integral desses idosos, seja por conflitos ou falta de tempo. Os vínculos e relações familiares influenciam diretamente a institucionalização.

Assinala-se que o sentimento de solidão e abandono se faz presente na evocação de um passado nem tão distante. Há um afastamento dos familiares, e os vínculos se esmorecem. 
Ao recordarem suas histórias vividas, criam vínculos, recebem atenção, contribuem com vivências, lembranças pessoais e coletivas, memórias sociais e históricas, o que proporciona benefícios como resgate da esperança de valor, dignidade, contato e experiências novas. Parafraseando a pesquisadora Ecléa Bosi, este estudo registra a voz e, através dela, a vida e o pensamento de sujeitos que já trabalharam por seus contemporâneos. A memória do trabalho é intensa e ocupa um lugar importante em suas recordações, e a memória coletiva recompõe o passado, pois outras pessoas ajudam a recordá-la.

Percebe-se que, ao propiciar aos idosos a possibilidade de construir narrativas sobre suas vidas, a afetividade circulou fortemente, marcando o encontro entre os participantes e a pesquisadora, mostrando, portanto, como a narrativa pode estabelecer elos e ressignificar quem os idosos foram, como se pudessem tocar as lembranças presentes no discurso. Demonstra-se estreita relação entre as histórias relatadas e as reminiscências que os idosos puderam lembrar. Estas memórias desenham suas vidas, pois são os retratos da sua história.

\section{LIVED STORIES AND MEMORIES}

\section{abstract}

This study aims to establish relationships between evoked memories and life stories of the institutionalized elderly. It presents a qualitative approach in a phenomenological basis, listing six residents of an institution for the aged (LTCF), all of which have preserved cognitive ability. The technique applied for the research is based on narrative interviews as data source using comprehensive biographical narratives. A priori categories, such as institutionalization, family relationships and working memory, and a posteriori categories, such as weather, health, historical memory and loneliness are analyzed. In the analysis of the results obtained a close relationship between the stories and reminiscences reported are shown. The narratives bring to light the background of the elderly until their institutionalization.

keywords

Institutionalized Elderly. Memories. Life Story.

\section{referências}

BOBBIO, Norberto. O tempo da memória: De Senectute e outros escritos autobiográficos. Rio de Janeiro: Campus, 1997.

BORN, Tomiko; BOECHAT, Norberto Seródio. A qualidade dos cuidados ao idoso institucionalizado. In: FREITAS, Elizabete Viana de et al. Tratado de Geriatria e Gerontologia. 3. ed. Rio de Janeiro: Guanabara Koogan, 2011. 
BOSI, Ecléa. Memória e sociedade: lembranças de velhos. 12. ed. São Paulo: Companhia das Letras, 1994.

BRASIL. Lei $n^{\circ} 10741$, de $1^{\circ}$ de outubro de 2003. Estatuto do Idoso. Disponível em <http://www.planalto.gov.br/ccivil_03/leis/2003/L10.741.html> Acesso em 11 abr. 2012.

Ministério da Saúde. Secretaria de Atenção à Saúde. Departamento de Ações Programáticas e Estratégicas. Área Técnica Saúde do Idoso. Atenção à Saúde da Pessoa Idosa e Envelhecimento. Brasília: Editora MS, 2010. 44 p.: il. Série B. Textos Básicos de Saúde. Série Pactos pela Saúde 2006, v. 12. Disponível em: <http://portal.saude. gov.br/portal/arquivos/pdf/volume12.pdf.> Acesso em 11 abr. 2012.

BUAES, Carolina Stumph. Sobre a construção de conhecimentos: uma experiência de educação financeira com mulheres idosas em um contexto popular. 2011. 259 f. Tese (Doutorado em Educação) - Faculdade de Educação, Universidade Federal do Rio Grande do Sul, Porto Alegre, 2011. Disponível em: <http://www.lume.ufrgs.br/ handle/10183/33670>. Acesso em: 12 nov. 2012.

CAMARANO, Ana Amélia; KANSO, Solange. As instituições de longa permanência para idosos no Brasil. Revista Brasileira de Estudos de População, São Paulo, v. 27, n. 1, p. 232-235, jan./jun. 2010. Disponível em: < http://www.scielo.br/pdf/rbepop/ v27n1/14.pdf >. Acesso em: 6 maio 2012.

CAMARANO, Ana Amélia et al. As instituições de longa permanência para idosos no Brasil. In: CAMARANO, Ana Amélia (Org.). Cuidados de Longa Duração para a População Idosa: um novo risco a ser assumido? Rio de Janeiro: Ipea, 2010.

CAMARANO, Ana Amélia; SCHARFSTEIN, Eloisa Adler. Instituições de Longa Permanência para Idosos: abrigo ou retiro? In: CAMARANO, Ana Amélia (Org.). Cuidados de Longa Duração para a População Idosa: um novo risco a ser assumido? Rio de Janeiro: Ipea, 2010.

DUARTE, Yeda Aparecida de Oliveira et al. Como estão sendo cuidados os idosos frágeis de São Paulo? A visão mostrada pelo Estudo SABE - Saúde, Bem-estar e Envelhecimento. In: CAMARANO, Ana Amélia (Org.). Cuidados de Longa Duração para a População Idosa: um novo risco a ser assumido? Rio de Janeiro: Ipea, 2010.

FERREIRA, Olívia G. L. et al. O envelhecimento ativo sob o olhar de idosos funcionalmente independentes. Revista da Escola de Enfermagem da USP, São Paulo, v. 44, n. 4, p. 1065-1069, dez. 2010.

FLICK, Uwe. Introdução à pesquisa qualitativa. 3. ed. Porto Alegre: Artmed, 2009.

GlL, Antonio Carlos. Métodos e Técnicas de Pesquisa Social. 6. ed. São Paulo: Atlas, 2011. GOFFMAN, Erwing. Manicômios, prisões e conventos. 8. ed. São Paulo: Perspectiva, 2010.

GUERRA, Ana Carolina Lima Cavaletti; CALDAS, Célia Pereira. Dificuldades e recompensas no processo de envelhecimento: a percepção do sujeito idoso. Ciência \& Saúde Coletiva, Rio de Janeiro, v. 15, n. 6, p. 2931-2940, set. 2010.

HALBWACHS, Maurice. A memória coletiva. 2. ed. São Paulo: Centauro, 2011.

LAMAS, Berenice Sica. As artistas: recortes do feminino no mundo das artes. Porto Alegre: Artes e Ofícios, 1997.

ROMERO, Dalia Elena et al. Internações de idosos por cuidados prolongados em hospitais do SUS no Rio de Janeiro: uma análise de suas características e da fragilidade das redes sociais de cuidado. In: CAMARANO, Ana Amélia (Org.). Cuidados de Longa Duração para a População Idosa: um novo risco a ser assumido? Rio de Janeiro: Ipea, 2010. 